\title{
In Situ Synthesis and Characterization of Polyethyleneimine-Modified Carbon Nanotubes Supported PtRu Electrocatalyst for Methanol Oxidation
}

\author{
Xi Geng, ${ }^{1}$ Jieying Jing, ${ }^{1,2}$ Yinjie Cen, ${ }^{1}$ Ravindra Datta, ${ }^{3}$ and Jianyu Liang ${ }^{1}$ \\ ${ }^{1}$ Department of Mechanical Engineering, Worcester Polytechnic Institute, 100 Institute Road, Worcester, MA 01609, USA \\ ${ }^{2}$ Key Laboratory of Coal Science and Technology of Shanxi Province and Ministry of Education, Taiyuan University of Technology, \\ Shanxi 030024, China \\ ${ }^{3}$ Department of Chemical Engineering, Worcester Polytechnic Institute, 100 Institute Road, Worcester, MA 01609, USA
}

Correspondence should be addressed to Jianyu Liang; jianyul@wpi.edu

Received 29 May 2014; Revised 19 November 2014; Accepted 26 November 2014

Academic Editor: Shijun Liao

Copyright $\odot 2015 \mathrm{Xi}$ Geng et al. This is an open access article distributed under the Creative Commons Attribution License, which permits unrestricted use, distribution, and reproduction in any medium, provided the original work is properly cited.

\begin{abstract}
$\mathrm{PtRu}$ bimetallic nanoparticles were successfully synthesized on polyethyleneimine- (PEI-) functionalized multiwalled carbon nanotubes (MWCNTs) via an effective and facile polyol reduction approach. Noncovalent surface modification of MWCNTs with PEI was confirmed by FTIR and zeta potential measurements. The morphology, crystalline structure, and composition of the hybrid material were characterized by transmission electron microscopy (TEM), scanning electron microscopy (SEM), X-ray powder diffraction (XRD), and energy dispersive X-ray spectroscopy (EDX), respectively. According to SEM and TEM observations, $\mathrm{PtRu}$ nanoparticles with narrow size distribution were homogeneously deposited on PEI-MWCNTs. Cyclic voltammetry tests demonstrated that the as-prepared PtRu/PEI-MWCNTs nanocomposite had a large electrochemical surface area and exhibited enhanced electrocatalytic activity towards methanol oxidation in comparison with oxidized MWCNTs as catalyst support. PEIfunctionalized CNTs, as useful building blocks for the assembly of Pt-based electrocatalyst, may have great potential for applications such as direct methanol fuel cell (DMFC).
\end{abstract}

\section{Introduction}

Over the past decade, carbon nanotubes (CNTs) with large active surface areas, excellent electronic conductivity, and high chemical stability have drawn considerable attention as an advanced supporting material for Pt-based catalysts $[1,2]$. Nevertheless, the surface of pristine CNTs is chemically inert and hydrophobic, which is unfavorable for the deposition of metal nanoparticles (NPs) [3, 4]. For this reason, CNTs are usually pretreated with concentrated acid to introduce hydroxyl and carboxyl functional groups. On the one hand, these functional groups can improve the solubility of the CNTs and provide preferential sites for the immobilization of noble metal catalysts [5]. On the other hand, this common modification method will disrupt the graphite structure of CNTs and result in the loss of electrical conductivity and the reduction of corrosion resistance [6].
In general, there are two strategies involving the preparation of CNTs and nanoparticles (NPs) hybrids. In addition to the direct deposition of preprocessed NPs onto CNTs, CNTs surfaces can also be decorated by NPs via covalent or noncovalent bonds. With an attempt to overcome the defected structure and disruption of delocalized $\pi$ electron systems caused by acid treatment, substantial efforts have been devoted to noncovalent functionalization of CNTs. As a versatile strategy, noncovalent functionalization of CNTs not only preserves the intrinsic structure of CNTs but also achieves the tailored properties of the nanocomposites (nanoworms, nanocubes, and nanoraspberries) [7-13]. Well-dispersed Pt nanoclusters on CNTs were prepared using bifunctional triphenylphosphine $\left(\mathrm{PPh}_{3}\right)$ or 1-aminopyrene (1-AP) as the interlinker, where the $\mathrm{PPh}_{3}$ or 1-AP molecules were strongly adsorbed on the CNTs through noncovalent-stacking interaction and electrostatic 
attractions [14-16]. CNTs modified by positively charged poly(diallyldimethylammonium chloride) (PDDA) have also been explored as templates for the deposition of Pt NPs with high density $[17,18]$. By using polymer wrapping technique, a controllable decoration of CNTs with poly(sodium 4-styrenesulfonate) (PSS) and Pt NPs in sequence was described by Kongkanand et al. [19]. In addition, a novel route towards the self-assembly of cetyltrimethylammonium bromide (CTAB) stabilized Pt nanocubics on PSS modified CNTs has also been demonstrated by means of electrostatic interaction [20].

Polyethyleneimine (PEI), as a polymeric surfactant, has been investigated as an alternative to PDDA to achieve surface functionalization of noble metal NPs through coordination effects. Cationic PDDA has been extensively reported to achieve the surface functionalization of CNTs by endowing positive charges on the surface and may offer certain advantages. For example, it was suggested by previous studies that the permeability of small organic molecules may be larger in PEI films compared with PDDA films because PEI had random branched chains while PDDA chains may be more compact $[21,22]$. Electrochemical study of different polyelectrolytes also observed different charge transfer behavior of linear and reticulated polyelectrolytes, with the former being considered as a linear chain of singly charged segment and the latter having more the characteristics of a multicharged ion [23]. Another study reported significant differences between the stabilizing efficiencies of PEI, PDDA, and poly(allylamine hydrochloride) (PAH) in synthesizing $\mathrm{PbS}$ nanoparticles and attributed the difference to their charge densities or their persistence lengths. Small monodispersed nanoparticles of $\mathrm{PbS}$ with a tight stabilizing shell were consistently found only when PEI was used [24].

Bai et al. presented a clean and efficient route to synthesize monodispersed Pt NPs via UV photoreduction of PEI mediated- $\mathrm{PtCl}_{6}{ }^{2-}$ anions [25]. Cheng and Jiang prepared PEI-functionalized MWCNTs by microwave method, where PEI served as anchoring sites for PtRu nanoparticles' selfassembling [26]. PEI was also conducted as a stabilizing agent to synthesize water-soluble $\mathrm{Pt} 20-25 \mathrm{~nm}$ ranged dendrites in dimethylformamide (DMF) [27]. Moreover, the aminorich $\mathrm{PEI}$ is known to be effectively attached on the sidewalls of CNTs via physisorption [28, 29]. Construction of onedimensional CNTs/metal NPs (metal = Au, Pt, Pd, Ag) heterogeneous nanostructures has been shown via chemical reduction of PEI-metal ion complexes adsorbed onto CNTs $[28,30,31]$.

In the pursuit of higher electrocatalytic activity and more stable performance, CNTs supported PtRu binary catalysts [32-34] have particularly been proven as the promising catalyst candidate for direct methanol fuel cell (DMFC). According to the bifunctional mechanism, the presence of $\mathrm{Ru}$ element could effectively modify the electronic nature of the $\mathrm{Pt}$ as well as remove the carbonaceous species to protect the Pt from being poisoned $[35,36]$. To our knowledge, even though tremendous progress has been made to tailor the size and shape of Pt NPs on CNTs, little research work has been conducted to control the morphology of bimetallic NPs by noncovalently functionalizing the surface of CNTs.

Herein, we present a simple and efficient synthesis route to anchor bimetallic PtRu electrocatalyst on PEI modified CNTs with tunable size and well-defined shape. Figure 1 illustrates the scheme of the immobilization of PtRu NPs on PEI-MWCNTs. The physiochemical and electrochemical properties of the as-prepared nanocomposites were characterized by zeta potential, FTIR, SEM, TEM, XRD, and cyclic voltammetry.

\section{Experimental}

2.1. Materials. Multiwalled carbon nanotubes (MWCNTs, $95 \%$ purity, diameter $=30 \mathrm{~nm}-60 \mathrm{~nm}$ ) were obtained from Helix Material Solutions, Inc. Potassium tetrachloroplatinate $\left(\mathrm{K}_{2} \mathrm{PtCl}_{4}, 98 \%\right)$, ruthenium chloride $\left(\mathrm{RuCl}_{3}, 98 \%\right)$, Nafion solution (5 wt\% in ethanol), ethylene glycol (EG, 99\%), and methanol (99\%) were purchased from Sigma-Aldrich. Polyethyleneimine (PEI $50 \mathrm{wt} \%$ in water, $\mathrm{Mw}=60,000$ ), sulfuric acid ( $98 \mathrm{wt} \%$ ), and nitric acid (69 wt \%) were obtained from Alfa Aesar. All the chemicals were used as received without further purification. Ultrapure Milli-Q water (resistivity $>18.2 \mathrm{M} \Omega \mathrm{cm}$ ) was exclusively used for making aqueous solutions and rinsing procedures.

2.2. PEI and Acid Functionalization of MWCNTs. Noncovalent functionalization of MWCNTs by PEI was carried out through a procedure adapted from literature $[28,31]$. Briefly, $100 \mathrm{mg}$ of MWCNTs was dispersed in $200 \mathrm{~mL} 1 \mathrm{wt} \%$ PEI aqueous solution, followed by ultrasonication for $3 \mathrm{~h}$ and magnetic stirring for $12 \mathrm{~h}$. Then, the stable PEI-MWCNTs suspension was filtered using a $0.2 \mu \mathrm{m}$ nylon filter membrane and rinsed to remove the excess PEI. MWCNTs were also functionalized by the conventional acid-oxidization method in which $100 \mathrm{mg}$ of pristine MWCNTs was refluxed in a $4 \mathrm{M} \mathrm{H}_{2} \mathrm{SO}_{4}$ and $4 \mathrm{MHNO}_{3}$ mixture at $120^{\circ} \mathrm{C}$ for $4 \mathrm{~h}$ [37]. The obtained oxidized MWNCTs were washed with copious water, filtered, and dried at $70^{\circ} \mathrm{C}$ overnight.

\subsection{Synthesis of MWCNTs Supported PtRu Electrocatalysts.} $\mathrm{PtRu} / \mathrm{PEI}-\mathrm{MWCNTs}$ catalyst was prepared by an in situ polyol reduction method. The typical procedure is as follows: PEI-CNT was dispersed in an EG solution under ultrasonic treatment and vigorous agitation; calculated amount of $\mathrm{K}_{2} \mathrm{PtCl}_{4}$ and $\mathrm{RuCl}_{3}$ with a molar ratio of $\mathrm{Pt}: \mathrm{Ru}=1: 1$ was added dropwise to achieve the nominal PtRu loading of $10 \mathrm{wt} \%, 30 \mathrm{wt} \%$, and $50 \mathrm{wt} \%$, respectively. The mixture was heated to $140^{\circ} \mathrm{C}$ and maintained for $3 \mathrm{~h}$ to completely reduce the metal precursors. A flow of ultrahigh purity nitrogen was also introduced to the reaction system to isolate oxygen and to remove organic byproducts during the synthesis step. After the deposition of PtRu NPs, the as-synthesized PtRu/PEIMWCNTs hybrid material was centrifugalized, rinsed repeatedly, and dried overnight. For comparison purpose, oxidized MWCNTs supported PtRu nanocomposite (denoted as $\mathrm{PtRu} / \mathrm{O}-\mathrm{MWCNTs}$ ) with $\mathrm{Pt}: \mathrm{Ru}$ atomic ratio of $1: 1$ and $30 \mathrm{wt} \%$ metal loading was also prepared and collected [38]. 

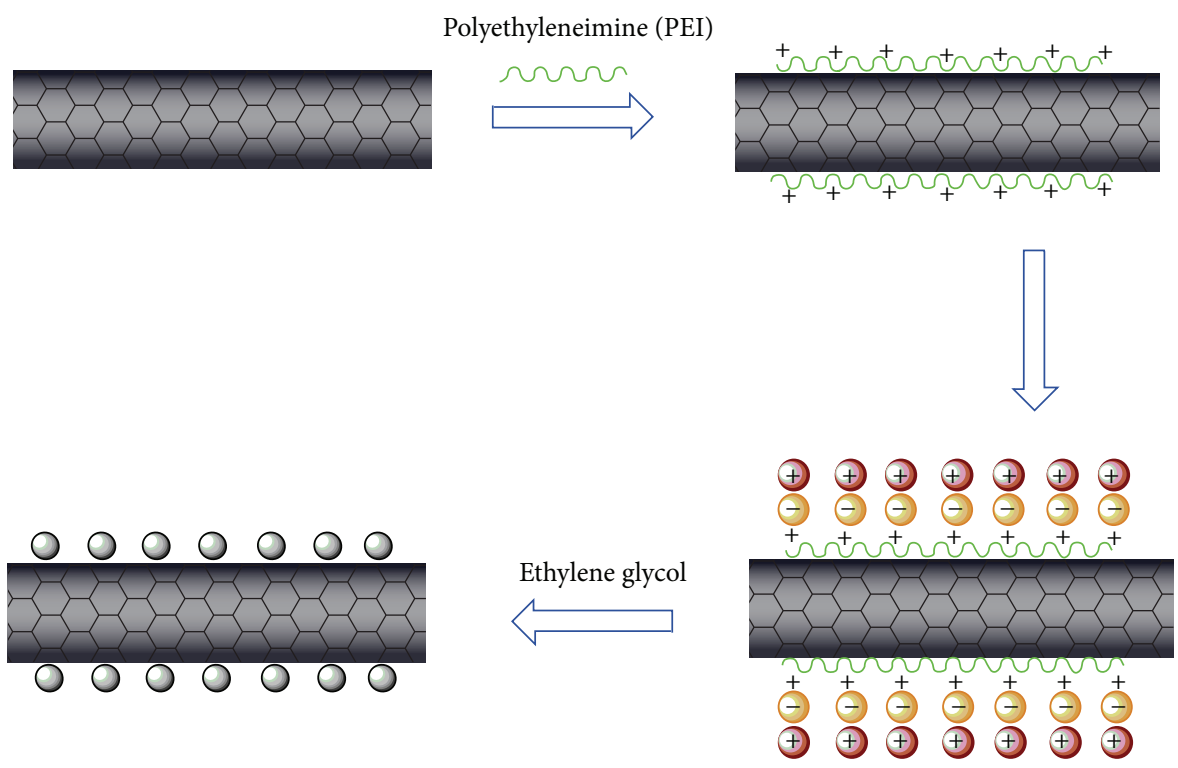

$\bigcirc \mathrm{PtRu}^{4}$ noparticle
$\odot \mathrm{PtCl}^{4-}$
$\left(\mathrm{Ru}^{3+}\right.$

FIgURE 1: Schematic of the synthesis of PtRu electrocatalyst on PEI-functionalized MWCNTs.

2.4. Physiochemical Characterization. To monitor the surface charge of MWCNTs, the zeta potential measurement was performed using a Malvern Zetasizer Nano ZS90. FTIR spectra were acquired by Brukeroptics Vetex70 spectrometer to further confirm the functionalization of MWCNTs with PEI. The morphology of the nanocomposite was studied by a JEOL 7000F scanning electron microscope (SEM) and JEOL 100CX ( $\mathrm{LaB}_{6}$ filament) transmission electron microscope (TEM) operating at an accelerating voltage of $100 \mathrm{kV}$. The presence of noble metal NPs is detected by energy dispersive X-ray analysis (EDX) and the X-ray diffraction (XRD) patterns of the samples were recorded using a Rigaku Geigerflex X-ray diffractometer with $\mathrm{Cu} \mathrm{K} \alpha$ radiation.

2.5. Electrochemical Analysis. Cyclic voltammetric measurements were carried out on a BASi 100B electrochemical analyzer with a conventional three-electrode cell. Glassy carbon electrode (GCE) ( $3 \mathrm{~mm}$ in diameter) was used as the working electrode, on which a thin layer of Nafion-impregnated $\mathrm{PtRu} / \mathrm{MWCNTs}$ catalyst was applied. The catalyst loading was fixed at $1 \mathrm{mg} / \mathrm{cm}^{2}$ for both the $30 \mathrm{wt} \% \mathrm{PtRu} / \mathrm{PEI}$-MWCNTs and $30 \mathrm{wt} \% \mathrm{PtRu} / \mathrm{O}-\mathrm{MWCNTs}$ modified GCE electrodes. Platinum wire served as the counter electrode and $\mathrm{Ag} / \mathrm{AgCl}$ electrode was used as the reference electrode. The electrochemical active surface area (ECSA) was calculated using cyclic voltammograms of the nanocomposite catalyst in the solution of $0.5 \mathrm{M} \mathrm{H}_{2} \mathrm{SO}_{4}$. The electrocatalytic activity for the methanol oxidation was characterized by cyclic voltammetry (CV) in a solution of $1 \mathrm{MCH}_{3} \mathrm{OH}+0.5 \mathrm{M} \mathrm{H}_{2} \mathrm{SO}_{4}$. The electrolyte solution was deaerated with ultrahigh purity $\mathrm{N}_{2}$ prior to the measurement and the entire experiment was conducted at room temperature.

\section{Results and Discussion}

3.1. Zeta Potential Measurement of PEI-MWCNTs Nanocomposite. Zeta potential is the electrical potential existing at the shear plane of a nanoparticle, which has been widely used to determine the surface charge at the electric double layer [18]. During the measurement, low concentration samples $(0.01 \mathrm{wt} \%)$ were dispersed in $1 \mathrm{mM} \mathrm{NaCl}$ solutions to ensure the constant ionic strength. The $\mathrm{pH}$ of the suspension was adjusted by adding either $\mathrm{HCl}$ or $\mathrm{NaOH}[18,39]$. The zeta potential as a function of $\mathrm{pH}$ for pristine and PEI-treated MWCNTs is shown in Figure 2. The pristine MWCNTs have a low isoelectric point $\left(\mathrm{pH}_{\mathrm{IEP}}\right)$ at 4.9 , whereas the $\mathrm{pH}_{\text {IEP }}$ moves to a more basic value at 8.1 after being treated by PEI. This result indicates that the cationic PEI polymer chains are noncovalently attached onto the MWCNTs surface. PEI are reported to form PEI-metal ion complexes with several metal compounds such as $\mathrm{K}_{2} \mathrm{PdCl}_{4}, \mathrm{~K}_{2} \mathrm{PtCl}_{4}$ [31], $\mathrm{AgNO}_{3}$ [40], and $\mathrm{CuCl}_{2}$ [41]. Hence, it is hypothesized that the positively charged amine groups of PEI could act as the anchor sites for the $\mathrm{PtCl}_{4}{ }^{2-}$ anions, followed by the electrostatic attraction of $\mathrm{Ru}^{3+}$ cations. In situ reduction of these noble metal precursors will facilitate the uniform dispersion of PtRu NPs on MWCNTs.

3.2. FTIR Spectra Analysis of PEI-Functionalized MWCNTs. The FTIR spectra of pristine MWCNTs and PEI-MWCNTs are shown in Figure 3. Three weak peaks at $1225 \mathrm{~cm}^{-1}$, $1578 \mathrm{~cm}^{-1}$, and $1630 \mathrm{~cm}^{-1}$ (marked by blue asterisks) reveal the graphite structure of pristine MWCNTs [42]. By comparison, one sharper adsorption peak at $1637 \mathrm{~cm}^{-1}$ (marked by red asterisks) is identified on the spectrum of PEI-MWCNTs, 


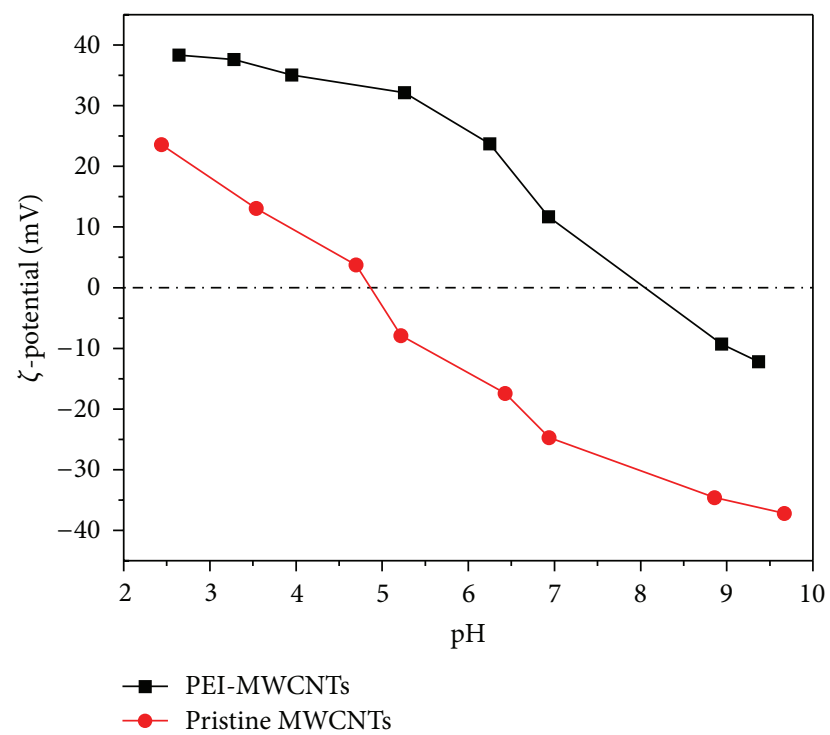

FIGURE 2: Zeta potential as a function of $\mathrm{pH}$ for pristine MWCNTs and PEI-MWCNTs.

which can be assigned to the bending vibration of $\mathrm{N}-\mathrm{H}$ $[37,42,43]$. These results verify the successful noncovalent modification of MWCNTs with PEI.

\subsection{Morphology of PtRu NPs Decorated on PEI-MWCNTs} and O-MWCNTs. Figure 4 shows the representative TEM micrographs and the corresponding particle size distribution histograms of the as-prepared electrocatalysts. In the case of $30 \mathrm{wt} \% \mathrm{PtRu} / \mathrm{O}-\mathrm{MWCNTs}$ (Figure 4(a)), the PtRu NPs are mainly distributed in the range of 2 to $8 \mathrm{~nm}$ and the mean particle size is estimated to be $4.3 \mathrm{~nm}$ using Gaussian fit (Figure 4(b)). Poor dispersion and obvious aggregation of $\mathrm{PtRu}$ nanocrystals on O-MWCNTs are observed, which is consistent with previous reports $[18,44,45]$. The formation of the agglomeration can be elucidated by the strong tendency of $\mathrm{PtRu}$ NPs to nucleate on the localized defect sites introduced by the harsh oxidation process. By contrast, PtRu NPs are homogeneously deposited on the external walls of PEI modified MWCNTs (Figures 4(c), 4(e), and 4(g)). For $10 \mathrm{wt} \% \mathrm{PtRu}$ loading, the NPs with the mean size of $2.6 \mathrm{~nm}$ are distinctively isolated from each other and sparsely dispersed on the surface of PEI-MWCNTs (Figure 4(d)). The particle size increases to $3.1 \mathrm{~nm}$ for $30 \mathrm{wt} \% \mathrm{PtRu} / \mathrm{PEI}-\mathrm{MWCNT}$ due to the existence of a small amount of nanoclusters. Despite the fact that the homogeneous coverage is still maintained on $50 \mathrm{wt} \%$ PEIMWCNTs (Figure 4), further increment in PtRu loading density gives rise to a continuous nanosheath structure, where almost all the NPs are interconnected with each other with the resulting particle size of $3.8 \mathrm{nms}$ on average. The relatively small particle size and narrow size distribution is probably attributed to the presence of PEI coating, providing abundant adsorption sites for PtRu precursors, thereby realizing the uniform assembly of metal NPs. Moreover, PEI may also serve as an effective stabilizer to isolate the adjacent noble metal nanocrystals from coalescence $[25,46]$.

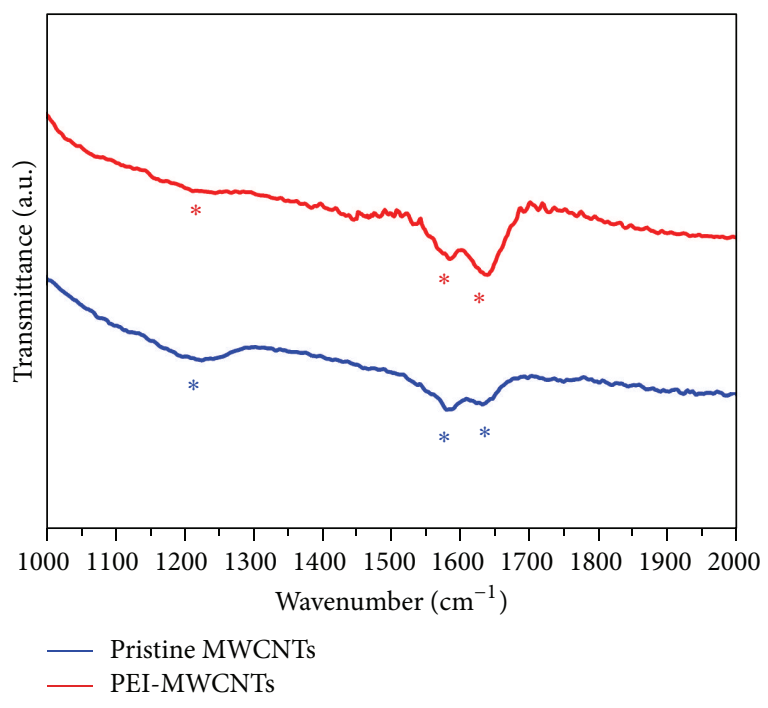

FIGURE 3: FTIR spectra of pristine MWCNTs and PEI-coated MWCNTs.

As shown in the SEM images (Figure 5(b)), PtRu NPs are evenly immobilized on PEI-MWCNTs. According to EDX analysis (Figure 6), the atomic ratio of Pt to Ru is almost $1: 1$, while the total PtRu loading is approximate to $30 \mathrm{wt} \%$, which is close to the initial feed ratio. For the sample with $10 \mathrm{wt} \%$ and $50 \mathrm{wt} \% \mathrm{PtRu}$ loading, we also obtained very consistent results. It is evident that the noble metal loading can be readily controlled by altering the concentration of the precursors.

3.4. X-Ray Diffraction Patterns of PtRu/MWCNTs Nanocomposites. The X-ray diffractograms of pristine MWCNTs, $\mathrm{PtRu} / \mathrm{PEI}-\mathrm{MWCNTs}$, and PtRu/O-MWCNTs nanocomposites are shown in Figure 7. The diffraction peaks at around $26.3^{\circ}, 43.0^{\circ}, 54.3^{\circ}$, and $79.8^{\circ}$ correspond to (002), (100), (004), and (110) of the graphite structures of MWCNTs. Although the acid oxidation procedures usually have detrimental effects on the graphene structure of MWCNTs, the graphite peaks of the oxidized MWCNT seem to be slightly higher than PEI modified MWCNT. This phenomenon can be explained by the physisorption of a thin layer of amorphous PEI coating on the surface of MWCNT, which causes attenuation of the graphite peak intensity in XRD pattern. The diffraction peaks for $\mathrm{PtRu} / \mathrm{O}-\mathrm{MWCNTs}$ at around $40.5^{\circ}, 47.5^{\circ}, 68.7^{\circ}$, and $81.8^{\circ}$ can be indexed to (111), (200), (220), and (311) crystalline planes of FCC (face-centered cubic) Pt, which shifted to high angle value with respect to pure FCC Pt (PDF card 4-802). This trend of peak displacements was also found for the PtRu/PEI-MWCNTs electrocatalyst with different PtRu loading, which implies the formation of $\mathrm{PtRu}$ alloy resulting from the incorporation of smaller $\mathrm{Ru}$ atoms into Pt phase [47, 48]. Since the standard reduction potentials of $\mathrm{PtCl}_{4}{ }^{2-} / \mathrm{Pt}$ and $\mathrm{Ru}^{3+} / \mathrm{Ru}$ are $0.758 \mathrm{~V}$ and $0.704 \mathrm{~V}$ (versus SHE) [49], respectively, there is a strong likelihood that the metal precursors were simultaneously reduced to PtRu alloy nanoparticles. In addition, no hcp Ru phase was identified on the XRD pattern, which further verified the formation of 


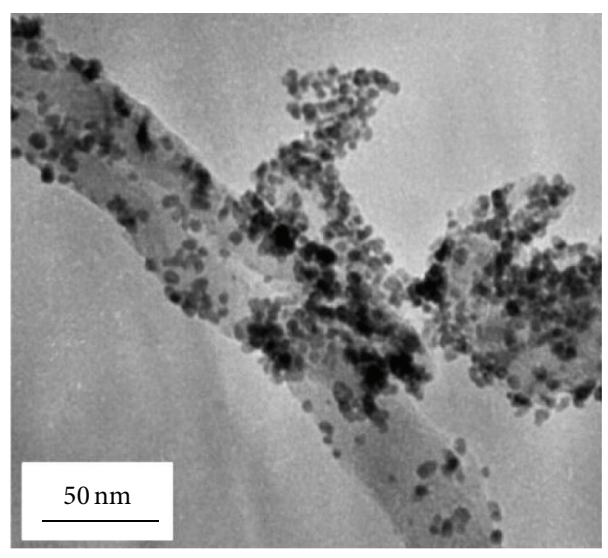

(a)

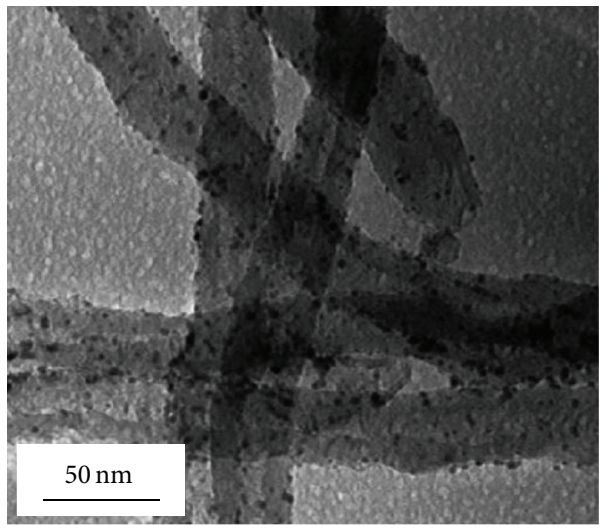

(c)

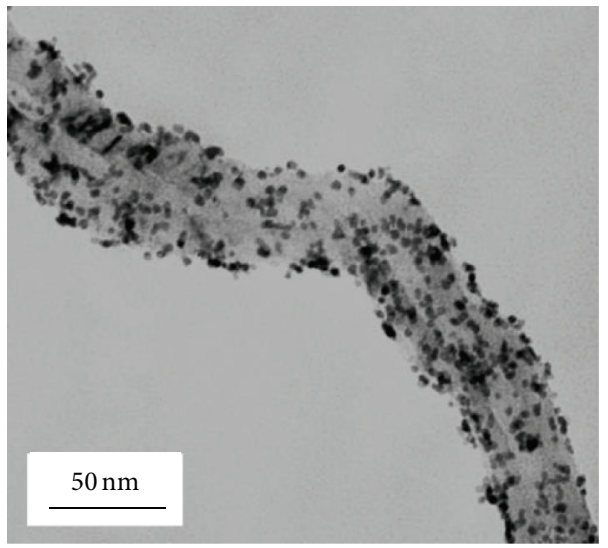

(e)

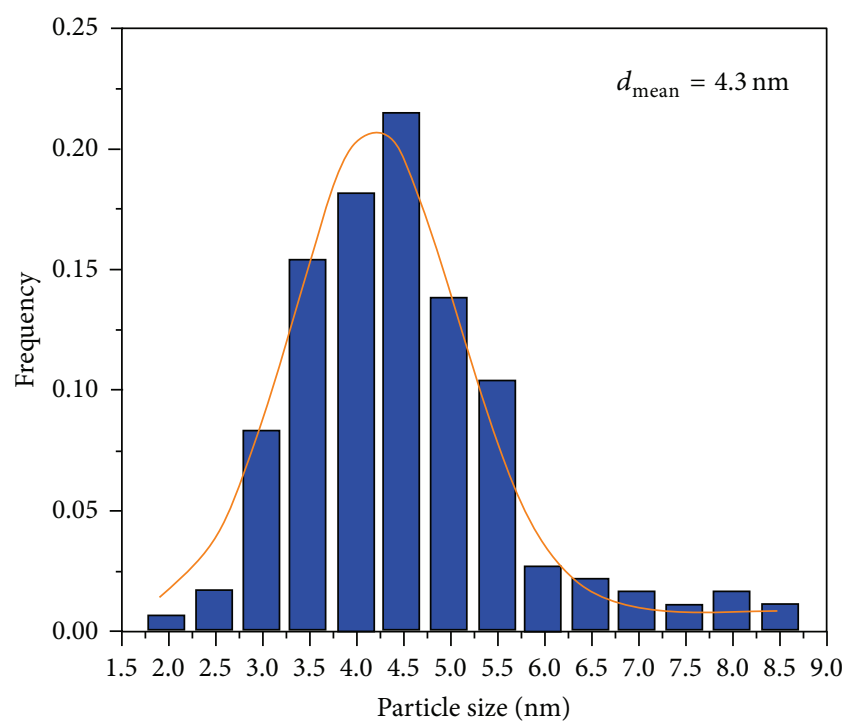

(b)

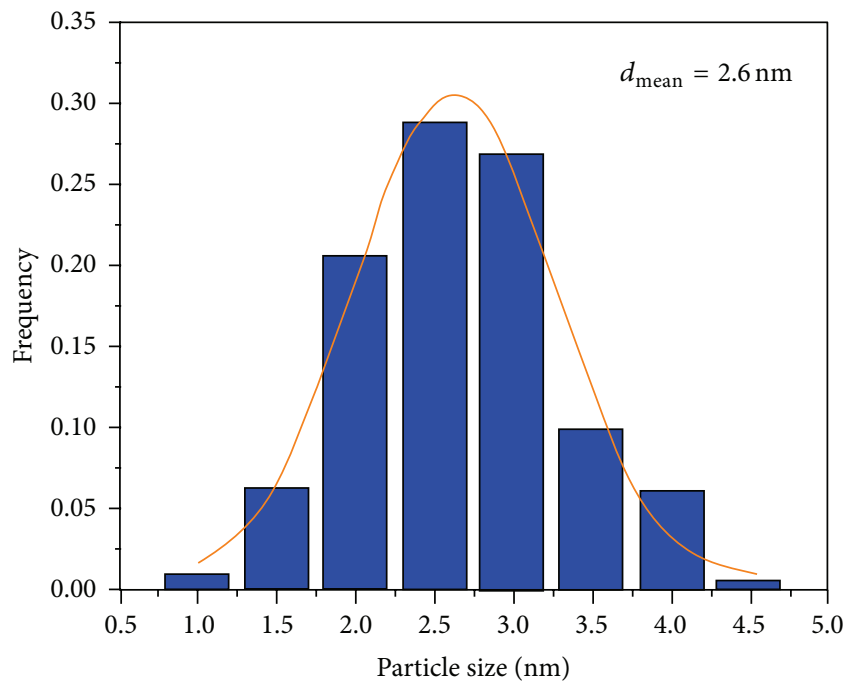

(d)

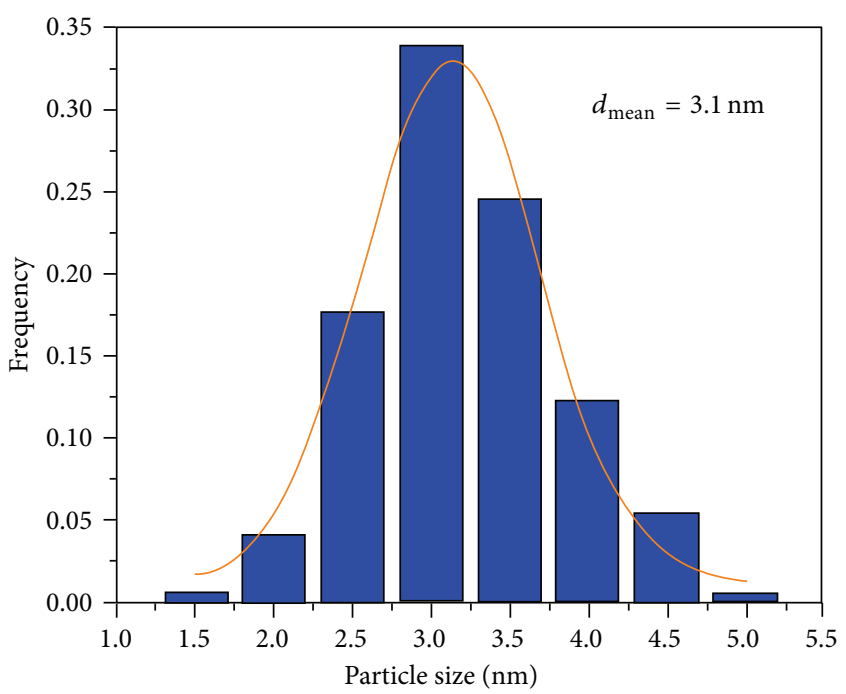

(f)

Figure 4: Continued. 


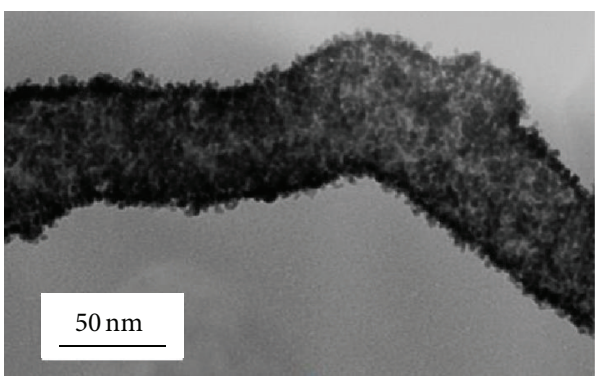

(g)

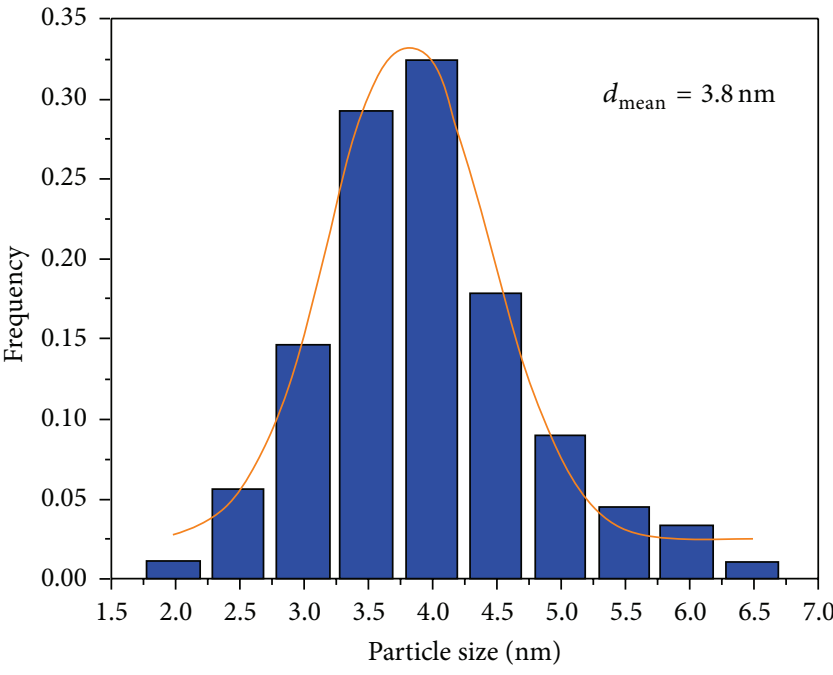

(h)

Figure 4: TEM images and the corresponding PtRu particle size distribution histograms of $30 \mathrm{wt} \% \mathrm{PtRu} / \mathrm{O}-\mathrm{MWCNTs}$ ((a), (b)); $10 \mathrm{wt} \%$ PtRu/PEI-MWCNTs ((c), (d)); 30 wt\% PtRu/PEI-MWCNTs ((e), (f)); and 50 wt\% PtRu/PEI-MWCNTs ((g), (h)).

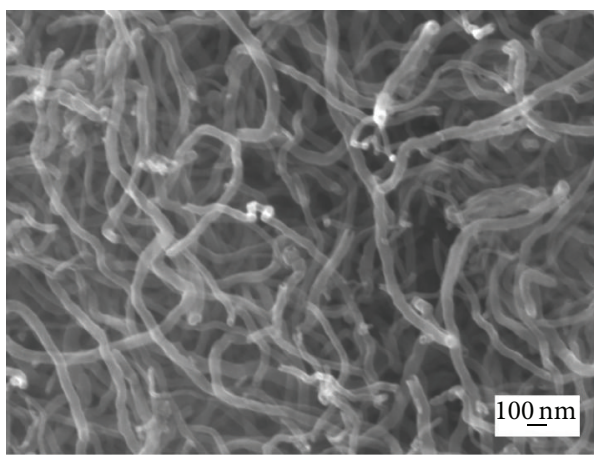

(a)

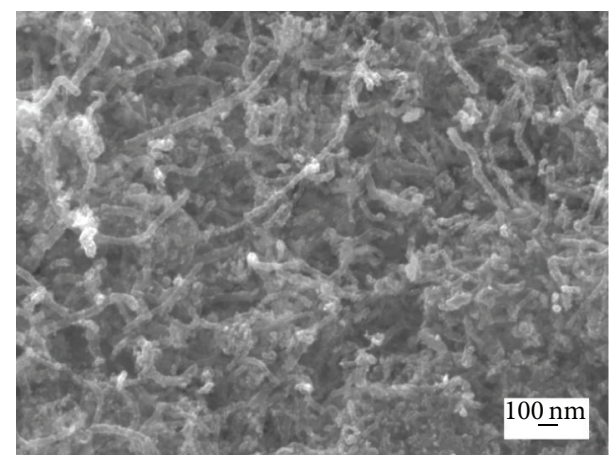

(b)

FIgure 5: SEM images of pristine MWCNTs (a), $30 \mathrm{wt} \% \mathrm{PtRu} / \mathrm{PEI}-\mathrm{MWCNTs}$ (b).

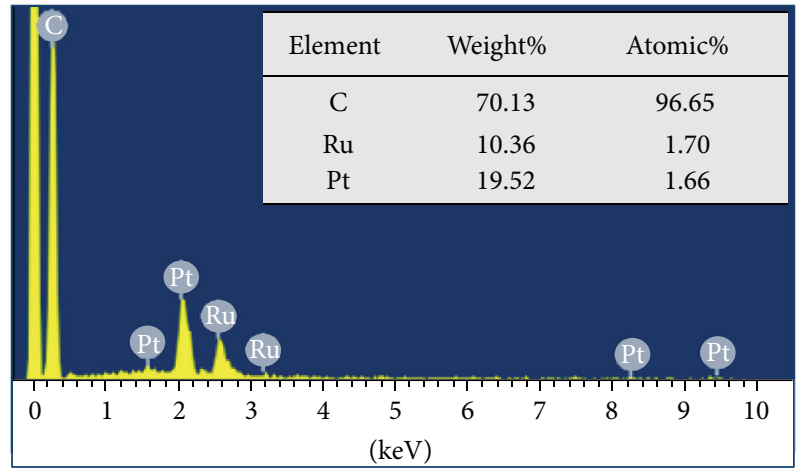

Figure 6: EDX spectrum of $30 \mathrm{wt} \%$ PtRu/PEI-MWCNTs.

bimetallic PtRu alloy rather than the separate phases of Pt and $\mathrm{Ru}$ NPs. According to the Scherer equation

$$
d=\frac{0.9 \lambda_{K \alpha}}{B_{2 \theta} \cdot \operatorname{Cos} \theta}
$$

where $d$ is the average particle size of PtRu NPs (nm), $\lambda_{K \alpha}$ is wavelength of X-ray $\left(\lambda_{K \alpha}=0.15406 \mathrm{~nm}\right), \theta$ is the peak angle, and $B_{2 \theta}$ is the full width half maximum in radians, the mean $\mathrm{PtRu}$ particle sizes are estimated to be 2.9 and $4.0 \mathrm{~nm}$ for $30 \mathrm{wt} \% \mathrm{PtRu} / \mathrm{PEI}-\mathrm{MWCNTs}$ and $30 \mathrm{wt} \% \mathrm{PtRu} / \mathrm{O}-\mathrm{MWCNTs}$ using the broadening of isolated (220) peak [50]. These results are in good agreement with TEM observations.

3.5. The Electrochemical Surface Area of the Nanocomposite Electrocatalyst. The hydrogen electrosorption voltammograms for $30 \mathrm{wt} \% \mathrm{PtRu} / \mathrm{PEI}-\mathrm{MWCNTs}$ and $30 \mathrm{wt} \% \mathrm{PtRu} / \mathrm{O}-$ MWCNTs electrocatalysts are shown in Figure 8. The characteristic peak in the region of $-0.2 \mathrm{~V}$ to $0.1 \mathrm{~V}$ can be attributed to atomic hydrogen adsorption on the Pt surface. And the ECSA for the catalysts can be estimated by the following equation:

$$
\mathrm{ECSA}=\frac{Q}{q^{0} \times M_{\mathrm{Pt}}},
$$

where $Q$ is the integrated area of the hydrogen desorption $(\mu \mathrm{C}), q^{0}$ is the charge for monolayer hydrogen adsorption 


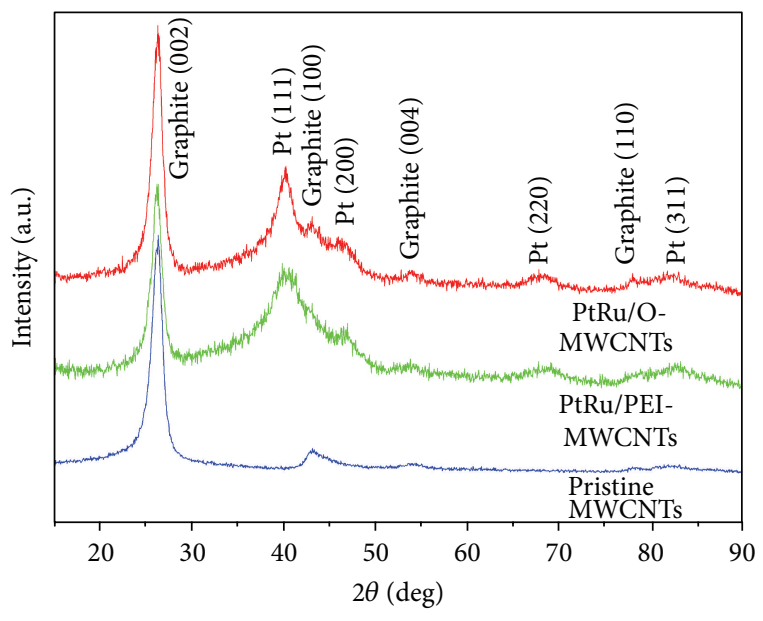

Figure 7: XRD patterns of pristine MWCNTs, $30 \mathrm{wt} \%$ PtRu/PEIMWCNTs, and $30 \mathrm{wt} \%$ PtRu/O-MWCNTs.

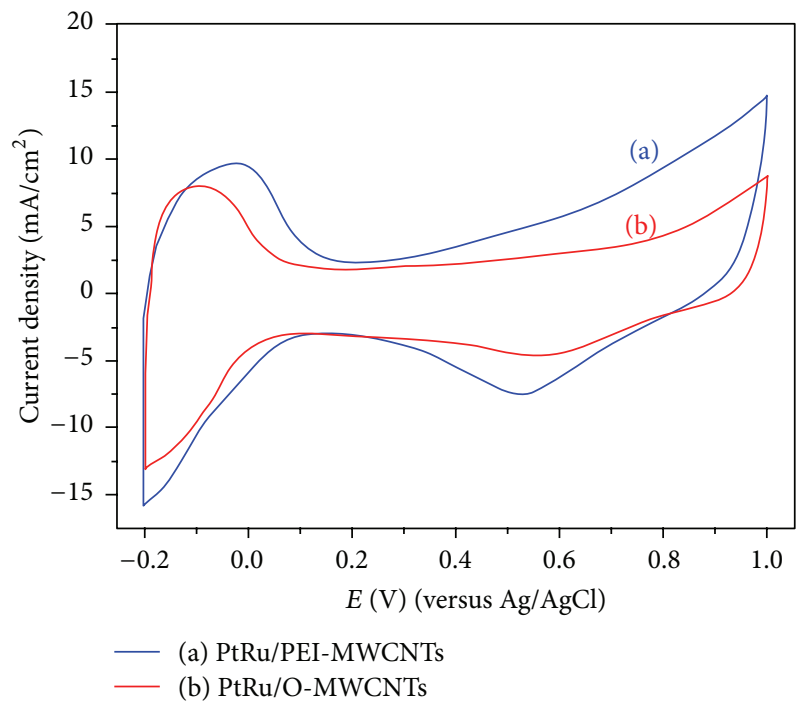

Figure 8: Cyclic voltammograms of PtRu (30 wt\% loading) supported on PEI-MWCNTs and O-MWCNTs in $0.5 \mathrm{M} \mathrm{H}_{2} \mathrm{SO}_{4}$ at a scan rate of $50 \mathrm{mV} / \mathrm{s}$ (the current densities are normalized by geometric surface area of the modified glassy carbon electrode).

on Pt, $q^{0}=210 \mathrm{C} \cdot \mathrm{cm}^{-2}$, a value generally admitted for polycrystalline Pt electrodes [51], and $M_{\mathrm{Pt}}$ is the mass of the Pt loading.

It is found that the PtRu/PEI-MWCNTs catalysts exhibit large ECSA around $81.7 \mathrm{~m}^{2} / \mathrm{g}_{\mathrm{Pt}}$ compared with $60.9 \mathrm{~m}^{2} / \mathrm{g}_{\mathrm{Pt}}$ for PtRu/O-MWCNTs. The larger ECSA of PtRu/PEIMWCNTs implies that more catalyst sites are accessible for electrochemical reactions, which can be attributed to the small particle size and high dispersion of PtRu NPs. Furthermore, it may also suggest that PEI coating on MWCNTs effectively prevent the PtRu nanoclusters from agglomeration and thus promote the electrocatalytic activity [25].

Since the ECSA alone cannot exactly represent the utilization efficiency of the noble metal, it is also necessary to investigate how many surface atoms are contributing to the electrochemical reactions. Thus, the ratio of ECSA to the geometrical specific surface areas $\left(S_{\text {geom }}\right)$ can be considered as an important indicator to evaluate the Pt utilization efficiency $[52,53]$. Here, the $S_{\text {geom }}$ can be calculated by

$$
\begin{gathered}
S_{\text {geom }}=\frac{6000}{\rho d}, \\
\rho_{\mathrm{PtRu}}=X_{\mathrm{Pt}} \rho_{\mathrm{Pt}}+X_{\mathrm{Ru}} \rho_{\mathrm{Ru}},
\end{gathered}
$$

where $d(\mathrm{~nm})$ is the mean particle diameter, $\rho\left(\mathrm{g} / \mathrm{cm}^{3}\right)$ is the density of NPs, $X$ is the weight fraction of metal, $\rho_{\mathrm{Pt}}=$ $21.4 \mathrm{~g} / \mathrm{cm}^{3}$, and $\rho_{\mathrm{Ru}}=12.3 \mathrm{~g} / \mathrm{cm}^{3}[48,50]$.

For $30 \mathrm{wt} \% \mathrm{PtRu} / \mathrm{O}-\mathrm{MWCNTs}$, the $S_{\text {geom }}$ and the utilization ratio are estimated to be $76.3 \mathrm{~m}^{2} / \mathrm{g}$ and $79.8 \%$, respectively. It is interesting to find that the $S_{\text {geom }}$ is $105.8 \mathrm{~m}^{2} / \mathrm{g}$ and the resulting utilization ratio is $77.2 \%$ for $30 \mathrm{wt} \% \mathrm{PtRu} / \mathrm{PEI}-$ MWCNTs. Similar utilization efficiency for both catalysts suggests that the methanol accessibility to the active sites of $\mathrm{PtRu}$ electrocatalyst will not be impeded by PEI coating on MWCNTs.

3.6. Electrocatalytic Activity of PtRu/MWCNTs towards Methanol Oxidation. Figure 9 illustrates the $\mathrm{CV}$ profiles of the electrocatalysts in $1 \mathrm{M} \mathrm{CH}_{3} \mathrm{OH}+0.5 \mathrm{M} \mathrm{H}_{2} \mathrm{SO}_{4}$. In the forward sweep, the featured methanol oxidation peaks are observed at approximately $0.70 \mathrm{~V}$ for $30 \mathrm{wt} \%$ PtRu/PEIMWCNTs and $30 \mathrm{wt} \% \mathrm{PtRu} / \mathrm{O}-\mathrm{MWCNTs}$. In the reverse scan, the anodic peak at $0.47 \mathrm{~V}$ is mainly associated with the removal of the residue carbonaceous species [54]. In principle, the onset potential of methanol oxidation is related to the breaking of $\mathrm{C}-\mathrm{H}$ bonds and the subsequent removal of intermediates such as $\mathrm{CO}_{\mathrm{ads}}$ by oxidation with $\mathrm{OH}_{\mathrm{ads}}$ species supplied by $\mathrm{Ru}-\mathrm{OH}$ sites $[6,55]$. Both the catalysts have comparable onset potential of methanol electrooxidation (MEO) at $0.3 \mathrm{~V}$ or so. This result indicates that the noncovalent modification of MWCNTs with PEI will not block the charge transfer during the electrocatalysis, and MEO is energetically favorable on the PtRu/PEI-MWCNTs nanocomposite. In addition, it is also worthwhile to note that the peak current density during the forward scan is $65.4 \mathrm{~mA} / \mathrm{cm}^{2}$ for PtRu/PEI-MWCNTs, almost 1.4 times as large as that of $\mathrm{PtRu} / \mathrm{O}-\mathrm{MWCNTs}$. This number is also higher than the commercial $\mathrm{PtRu} / \mathrm{C}$ catalyst with current density of $17.4 \mathrm{~mA} / \mathrm{cm}^{2}$ in sweep rate $50 \mathrm{mV} / \mathrm{s}$ [56]. The significant improvement in the catalytic activity for MEO is most likely due to the high ECSA of the former catalyst.

\subsection{Long-Term Durability of PtRu/MWCNTs towards Metha-} nol Oxidation. The stabilities of $30 \mathrm{wt} \% \mathrm{PtRu} / \mathrm{PEI}-\mathrm{MWCNTs}$ and $30 \mathrm{wt} \% \mathrm{PtRu} / \mathrm{O}-\mathrm{MWCNTs}$ electrocatalysts towards MEO were examined by potential cycling between $-0.2 \mathrm{~V}$ and $1 \mathrm{~V}$ (versus $\mathrm{Ag} / \mathrm{AgCl}$ ) in $1 \mathrm{M} \mathrm{CH}_{3} \mathrm{OH}+0.5 \mathrm{M} \mathrm{H}_{2} \mathrm{SO}_{4}$. As shown in Figure 10, the forward peak current density $\left(I_{f}\right)$ increases initially and reaches the maximum value after 40 cycles for both electrocatalysts and it is followed by a gradual decay of $I_{f}$ during the successive $\mathrm{CV}$ scans. Using the peak current density measured after 40 cycles 


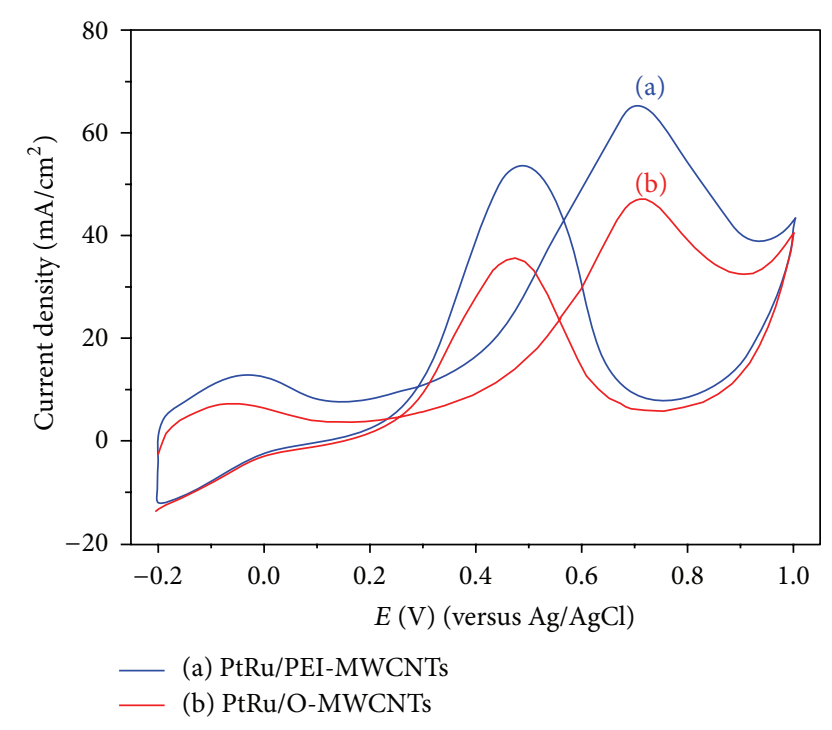

FIgUre 9: Cyclic voltammograms of PtRu (30 wt\% loading) supported on PEI-MWCNTs and O-MWCNTs in $0.5 \mathrm{M} \mathrm{H}_{2} \mathrm{SO}_{4}+$ $1 \mathrm{M} \mathrm{CH} \mathrm{CH}_{3} \mathrm{OH}$ at a scan rate of $50 \mathrm{mV} / \mathrm{s}$ (the current densities are normalized by geometric surface area of the modified glassy carbon electrode).

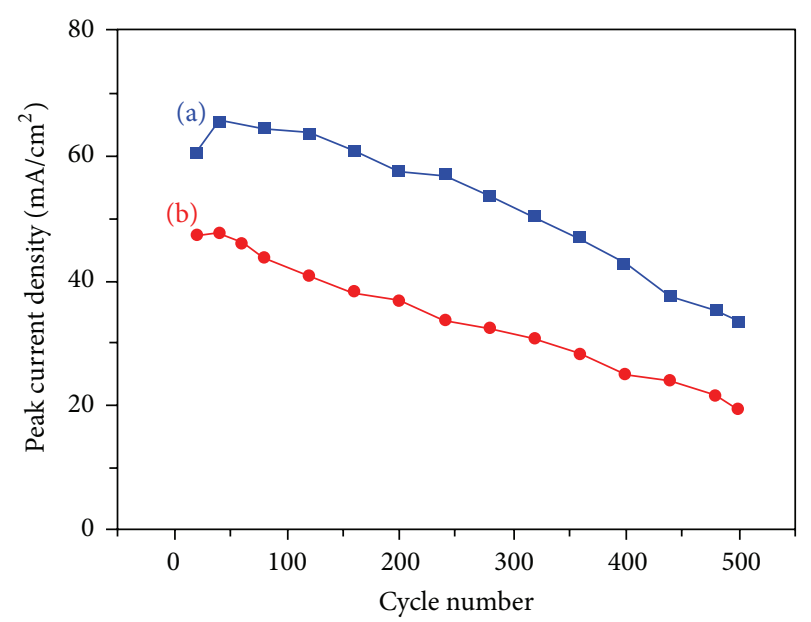

(a) PtRu/PEI-MWCNTs

(b) PtRu/O-MWCNTs

Figure 10: Long-term stability of PtRu (30 wt\% loading) supported on PEI-MWCNTs and O-MWCNTs in $0.5 \mathrm{M} \mathrm{H}_{2} \mathrm{SO}_{4}+1 \mathrm{M} \mathrm{CH}_{3} \mathrm{OH}$ at a scan rate of $50 \mathrm{mV} / \mathrm{s}$.

$\left(I_{0}\right)$ as the reference, the anodic peak current density $\left(I_{f}\right)$ is about $55 \%$ of $I_{0}$ for $30 \mathrm{wt} \% \mathrm{PtRu} / \mathrm{PEI}-\mathrm{MWCNTs}$ after $\mathrm{CV}$ scanning for 500 cycles, whereas the ratio of $I_{f} / I_{0}$ is only $42 \%$ for $30 \mathrm{wt} \% \mathrm{PtRu} / \mathrm{O}-\mathrm{MWCNTs}$. In general, the loss of catalytic activity with the increase of cycles may result from methanol consumption, increase in catalyst particles size, and accumulation of poisoning carbonaceous species on the electrode surface [57]. In comparison with $\mathrm{PtRu} / \mathrm{O}-$ MWCNTs, the relatively higher ratio of $I_{f} / I_{0}$ indicates that $\mathrm{PtRu} / \mathrm{PEI}-\mathrm{MWCNTs}$ are more durable for electrooxidation of methanol. The enhanced durability is probably associated with the homogeneous dispersion of uniform-sized PtRu nanoparticles on PEI-MWCNTs support, which could effectively mitigate the catalyst coarsening during the long-term potential cycling. A detailed and statistically meaningful study comparing the morphology of PtRu catalyst system before and after cycling is undergoing and will be presented in our next paper.

\section{Conclusions}

In summary, we presented an efficient and novel method to tether PtRu bimetallic NPs on the surface of PEI modified MWCNTs. Compared with the conventional acid-oxidization procedure, noncovalent functionalization of MWCNTs with PEI preserved the integrity of graphite structure and favored the uniform dispersion of PtRu NPs. The CV characterizations demonstrated that PtRu/PEI-MWCNTs nanocomposite exhibited superior electrocatalytic performance, which might be a promising anode catalyst for DMFCs.

\section{Conflict of Interests}

The authors declare that there is no conflict of interests regarding the publication of this paper.

\section{References}

[1] M. S. Saha, R. Li, and X. Sun, "High loading and monodispersed Pt nanoparticles on multiwalled carbon nanotubes for high performance proton exchange membrane fuel cells," Journal of Power Sources, vol. 177, no. 2, pp. 314-322, 2008.

[2] Y.-J. Gu and W.-T. Wong, "Nanostructure PtRu/MWNTs as anode catalysts prepared in a vacuum for direct methanol oxidation," Langmuir, vol. 22, no. 26, pp. 11447-11452, 2006.

[3] C.-C. Chen, C.-F. Chen, C.-M. Chen, and F.-T. Chuang, "Modification of multi-walled carbon nanotubes by microwave digestion method as electrocatalyst supports for direct methanol fuel cell applications," Electrochemistry Communications, vol. 9, no. 1, pp. 159-163, 2007.

[4] C. Hu, Y. Cao, L. Yang et al., "Preparation of highly dispersed Pt-SnOx nanoparticles supported on multi-walled carbon nanotubes for methanol oxidation," Applied Surface Science, vol. 257, no. 18, pp. 7968-7974, 2011.

[5] B. Wu, Y. Kuang, X. Zhang, and J. Chen, "Noble metal nanoparticles/carbon nanotubes nanohybrids: synthesis and applications," Nano Today, vol. 6, no. 1, pp. 75-90, 2011.

[6] Y. Zhao, X. Yang, J. Tian, F. Wang, and L. Zhan, "A facile and novel approach toward synthetic polypyrrole oligomers functionalization of multi-walled carbon nanotubes as PtRu catalyst support for methanol electro-oxidation," Journal of Power Sources, vol. 195, no. 15, pp. 4634-4640, 2010.

[7] G. Wei, C. Pan, J. Reichert, and K. D. Jandt, "Controlled assembly of protein-protected gold nanoparticles on noncovalent functionalized carbon nanotubes," Carbon, vol. 48, no. 3, pp. 645-653, 2010

[8] H. Dai and R. J. Chen, "Noncovalent sidewall functionalization of carbon nanotubes," Google Patents US 10/473,101, 2011.

[9] S.-N. Ding, D. Shan, S. Cosnier, and A. le Goff, "Single-walled carbon nanotubes noncovalently functionalized by ruthenium(II) complex tagged with pyrene: electrochemical and 
electrogenerated chemiluminescence properties," ChemistryA European Journal, vol. 18, no. 37, pp. 11564-11568, 2012.

[10] S. Murugesan, K. Myers, and V. R. Subramanian, "Aminofunctionalized and acid treated multi-walled carbon nanotubes as supports for electrochemical oxidation of formic acid," Applied Catalysis B: Environmental, vol. 103, no. 3-4, pp. 266274, 2011.

[11] A. Takai, H. Ataee-Esfahani, Y. Doi, M. Fuziwara, Y. Yamauchi, and K. Kuroda, "Pt nanoworms: creation of a bumpy surface on one-dimensional (1D) Pt nanowires with the assistance of surfactants embedded in mesochannels," Chemical Communications, vol. 47, no. 27, pp. 7701-7703, 2011.

[12] B. Wu, N. Zheng, and G. Fu, "Small molecules control the formation of Pt nanocrystals: a key role of carbon monoxide in the synthesis of Pt nanocubes," Chemical Communications, vol. 47, no. 3, pp. 1039-1041, 2011.

[13] S. I. Lim, I. Ojea-Jiménez, M. Varon, E. Casals, J. Arbiol, and V. Puntes, "Synthesis of platinum cubes, polypods, cuboctahedrons, and raspberries assisted by cobalt nanocrystals," Nano Letters, vol. 10, no. 3, pp. 964-973, 2010.

[14] X. Li, Y. Liu, L. Fu, L. Cao, D. Wei, and Y. Wang, "Efficient synthesis of carbon nanotube-nanoparticle hybrids," Advanced Functional Materials, vol. 16, no. 18, pp. 2431-2437, 2006.

[15] Y. Mu, H. Liang, J. Hu, L. Jiang, and L. Wan, "Controllable Pt nanoparticle deposition on carbon nanotubes as an anode catalyst for direct methanol fuel cells," The Journal of Physical Chemistry B, vol. 109, no. 47, pp. 22212-22216, 2005.

[16] K. Kardimi, T. Tsoufis, A. Tomou, B. J. Kooi, M. I. Prodromidis, and D. Gournis, "Synthesis and characterization of carbon nanotubes decorated with $\mathrm{Pt}$ and PtRu nanoparticles and assessment of their electrocatalytic performance," International Journal of Hydrogen Energy, vol. 37, no. 2, pp. 1243-1253, 2012.

[17] N. Du, H. Zhang, P. Wu, J. Yu, and D. Yang, "A general approach for uniform coating of a metal layer on MWCNTs via layer-bylayer assembly," The Journal of Physical Chemistry C, vol. 113, no. 40, pp. 17387-17391, 2009.

[18] S. Wang, S. P. Jiang, and X. Wang, "Polyelectrolyte functionalized carbon nanotubes as a support for noble metal electrocatalysts and their activity for methanol oxidation," Nanotechnology, vol. 19, no. 26, Article ID 265601, 2008.

[19] A. Kongkanand, K. Vinodgopal, S. Kuwabata, and P. V. Kamat, "Highly dispersed Pt catalysts on single-walled carbon nanotubes and their role in methanol oxidation," The Journal of Physical Chemistry B, vol. 110, no. 33, pp. 16185-16188, 2006.

[20] W. Yang, X. Wang, F. Yang, C. Yang, and X. Yang, "Carbon nanotubes decorated with $\mathrm{Pt}$ nanocubes by a noncovalent functionalization method and their role in oxygen reduction," Advanced Materials, vol. 20, no. 13, pp. 2579-2587, 2008.

[21] L. Shi, Z. Song, J. Huang et al., "Effects of the type of polycation on the amperometric response of choline biosensors prepared by a layer-by-layer deposition technique," Materials Science and Engineering C, vol. 25, no. 4, pp. 433-435, 2005.

[22] C. Schüler and F. Caruso, "Preparation of enzyme multilayers on colloids for biocatalysis," Macromolecular Rapid Communications, vol. 21, no. 11, pp. 750-753, 2000.

[23] S. Ulmeanu, H. J. Lee, and H. H. Girault, "Voltammetric characterisation of polyelectrolyte adsorption/transfer at the water-1,2-DCE interface," Electrochemistry Communications, vol. 3, no. 10, pp. 539-543, 2001.

[24] E. Koupanou, S. Ahualli, O. Glatter, A. Delgado, F. Krumeich, and E. Leontidis, "Stabilization of lead sulfide nanoparticles by polyamines in aqueous solutions. A structural study of the dispersions," Langmuir, vol. 26, no. 22, pp. 16909-16920, 2010.

[25] L. Bai, H. Zhu, J. S. Thrasher, and S. C. Street, "Synthesis and electrocatalytic activity of photoreduced platinum nanoparticles in a poly(ethylenimine) matrix," ACS Applied Materials and Interfaces, vol. 1, no. 10, pp. 2304-2311, 2009.

[26] Y. Cheng and S. P. Jiang, "Highly effective and CO-tolerant PtRu electrocatalysts supported on poly(ethyleneimine) functionalized carbon nanotubes for direct methanol fuel cells," Electrochimica Acta, vol. 99, pp. 124-132, 2013.

[27] S. Mourdikoudis, M. Chirea, T. Altantzis et al., "Dimethylformamide-mediated synthesis of water-soluble platinum nanodendrites for ethanol oxidation electrocatalysis," Nanoscale, vol. 5, no. 11, pp. 4776-4784, 2013.

[28] X. Hu, T. Wang, L. Wang, S. Guo, and S. Dong, "A general route to prepare one- and three-dimensional carbon nanotube/metal nanoparticle composite nanostructures," Langmuir, vol. 23, no. 11, pp. 6352-6357, 2007.

[29] S.-C. Yi, C. Y. Jung, and W. J. Kim, "Synthesis of Pt/PEIMWCNT composite materials on polyethyleneimine-functionalized MWNTs as supports," Materials Research Bulletin, vol. 46, no. 12, pp. 2433-2440, 2011.

[30] X. Hu, T. Wang, X. Qu, and S. Dong, "In situ synthesis and characterization of multiwalled carbon nanotube/Au nanoparticle composite materials," The Journal of Physical Chemistry B, vol. 110, no. 2, pp. 853-857, 2006.

[31] J. Li, W. Yang, H. Zhu et al., "In situ PEI and formic acid directed formation of Pt NPs/MWNTs hybrid material with excellent electrocatalytic activity," Talanta, vol. 79, no. 3, pp. 935-939, 2009.

[32] C. Bock, C. Paquet, M. Couillard, G. A. Botton, and B. R. MacDougall, "Size-selected synthesis of PtRu nano-catalysts: reaction and size control mechanism," Journal of the American Chemical Society, vol. 126, no. 25, pp. 8028-8037, 2004.

[33] C. Bock, M.-A. Blakely, and B. MacDougall, "Characteristics of adsorbed $\mathrm{CO}$ and $\mathrm{CH}_{3} \mathrm{OH}$ oxidation reactions for complex $\mathrm{Pt} / \mathrm{Ru}$ catalyst systems," Electrochimica Acta, vol. 50, no. 12, pp. 2401-2414, 2005.

[34] M. K. Jeon, J. S. Cooper, and P. J. McGinn, "Investigation of $\mathrm{PtCoCr} / \mathrm{C}$ catalysts for methanol electro-oxidation identified by a thin film combinatorial method," Journal of Power Sources, vol. 192, no. 2, pp. 391-395, 2009.

[35] H. A. Gasteiger, N. Markovic, P. N. Ross Jr., and E. J. Cairns, "Methanol electrooxidation on well-characterized platinumruthenium bulk alloys," The Journal of Physical Chemistry, vol. 97, no. 46, pp. 12020-12029, 1993.

[36] T. Iwasita, F. C. Nart, and W. Vielstich, "An FTIR study of the catalytic activity of a 85:15 Pt. Ru alloy for methanol oxidation," Berichte der Bunsengesellschaft für physikalische Chemie, vol. 94, no. 9, pp. 1030-1034, 1990.

[37] W. Li, C. Liang, W. Zhou et al., "Preparation and characterization of multiwalled carbon nanotube-supported platinum for cathode catalysts of direct methanol fuel cells," The Journal of Physical Chemistry B, vol. 107, no. 26, pp. 6292-6299, 2003.

[38] V. Lordi, N. Yao, and J. Wei, "Method for supporting platinum on single-walled carbon nanotubes for a selective hydrogenation catalyst," Chemistry of Materials, vol. 13, no. 3, pp. 733-737, 2001.

[39] L. Jiang and L. Gao, "Modified carbon nanotubes: an effective way to selective attachment of gold nanoparticles," Carbon, vol. 41, no. 15, pp. 2923-2929, 2003. 
[40] J. Dai and M. L. Bruening, "Catalytic nanoparticles formed by reduction of metal ions in multilayered polyelectrolyte films," Nano Letters, vol. 2, no. 5, pp. 497-501, 2002.

[41] H.-X. Wu, W.-M. Cao, Y. Li et al., "In situ growth of copper nanoparticles on multiwalled carbon nanotubes and their application as non-enzymatic glucose sensor materials," Electrochimica Acta, vol. 55, no. 11, pp. 3734-3740, 2010.

[42] G. Zou, H. Yang, M. Jain et al., "Vertical connection of carbon nanotubes to silicon at room temperature using a chemical route," Carbon, vol. 47, no. 4, pp. 933-937, 2009.

[43] N. Jia, Q. Lian, H. Shen, C. Wang, X. Li, and Z. Yang, "Intracellular delivery of quantum dots tagged antisense oligodeoxynucleotides by functionalized multiwalled carbon nanotubes," Nano Letters, vol. 7, no. 10, pp. 2976-2980, 2007.

[44] S. Wang, X. Wang, and S. P. Jiang, "PtRu nanoparticles supported on 1-aminopyrene-functionalized multiwalled carbon nanotubes and their electrocatalytic activity for methanol oxidation," Langmuir, vol. 24, no. 18, pp. 10505-10512, 2008.

[45] P. Guo, H. H. Song, and X. H. Chen, "Electrochemical performance of graphene nanosheets as anode material for lithiumion batteries," Electrochemistry Communications, vol. 11, no. 6, pp. 1320-1324, 2009.

[46] T. Li, Y. Du, and E. Wang, "Polyethyleneimine-functionalized platinum nanoparticles with high electrochemiluminescence activity and their applications to amplified analysis of biomolecules," Chemistry-An Asian Journal, vol. 3, no. 11, pp. 1942-1948, 2008.

[47] E. Antolini and F. Cardellini, "Formation of carbon supported PtRu alloys: an XRD analysis," Journal of Alloys and Compounds, vol. 315, no. 1-2, pp. 118-122, 2001.

[48] J. Guo, G. Sun, S. Shiguo et al., "Polyol-synthesized PtRu/C and PtRu black for direct methanol fuel cells," Journal of Power Sources, vol. 168, no. 2, pp. 299-306, 2007.

[49] A. J. Bard and L. R. Faulkner, Electrochemical MethodsFundamental and Applications, John Wiley \& Sons, New York, NY, USA, 2nd edition, 2001.

[50] G. Wu and B.-Q. Xu, "Carbon nanotube supported Pt electrodes for methanol oxidation: a comparison between multi- and single-walled carbon nanotubes," Journal of Power Sources, vol. 174, no. 1, pp. 148-158, 2007.

[51] N. Tian, Z.-Y. Zhou, S.-G. Sun, Y. Ding, and L. W. Zhong, "Synthesis of tetrahexahedral platinum nanocrystals with highindex facets and high electro-oxidation activity," Science, vol. 316, no. 5825, pp. 732-735, 2007.

[52] C. Zhou, H. Wang, F. Peng, J. Liang, H. Yu, and J. Yang, " $\mathrm{MnO}_{2} / \mathrm{CNT}$ supported Pt and PtRu nanocatalysts for direct methanol fuel cells," Langmuir, vol. 25, no. 13, pp. 7711-7717, 2009.

[53] T. Thampan, S. Malhotra, J. Zhang, and R. Datta, "PEM fuel cell as a membrane reactor," Catalysis Today, vol. 67, no. 1-3, pp. 1532, 2001.

[54] A. Halder, S. Sharma, M. S. Hegde, and N. Ravishankar, "Controlled attachment of ultrafine platinum nanoparticles on functionalized carbon nanotubes with high electrocatalytic activity for methanol oxidation," The Journal of Physical Chemistry C, vol. 113, no. 4, pp. 1466-1473, 2009.

[55] R. Chetty, S. Kundu, W. Xia et al., "PtRu nanoparticles supported on nitrogen-doped multiwalled carbon nanotubes as catalyst for methanol electrooxidation," Electrochimica Acta, vol. 54, no. 17, pp. 4208-4215, 2009.
[56] S. Liao, K.-A. Holmes, H. Tsaprailis, and V. I. Birss, "High performance PtRulr catalysts supported on carbon nanotubes for the anodic oxidation of methanol," Journal of the American Chemical Society, vol. 128, no. 11, pp. 3504-3505, 2006.

[57] V. Selvaraj and M. Alagar, "Pt and Pt-Ru nanoparticles decorated polypyrrole/multiwalled carbon nanotubes and their catalytic activity towards methanol oxidation," Electrochemistry Communications, vol. 9, no. 5, pp. 1145-1153, 2007. 

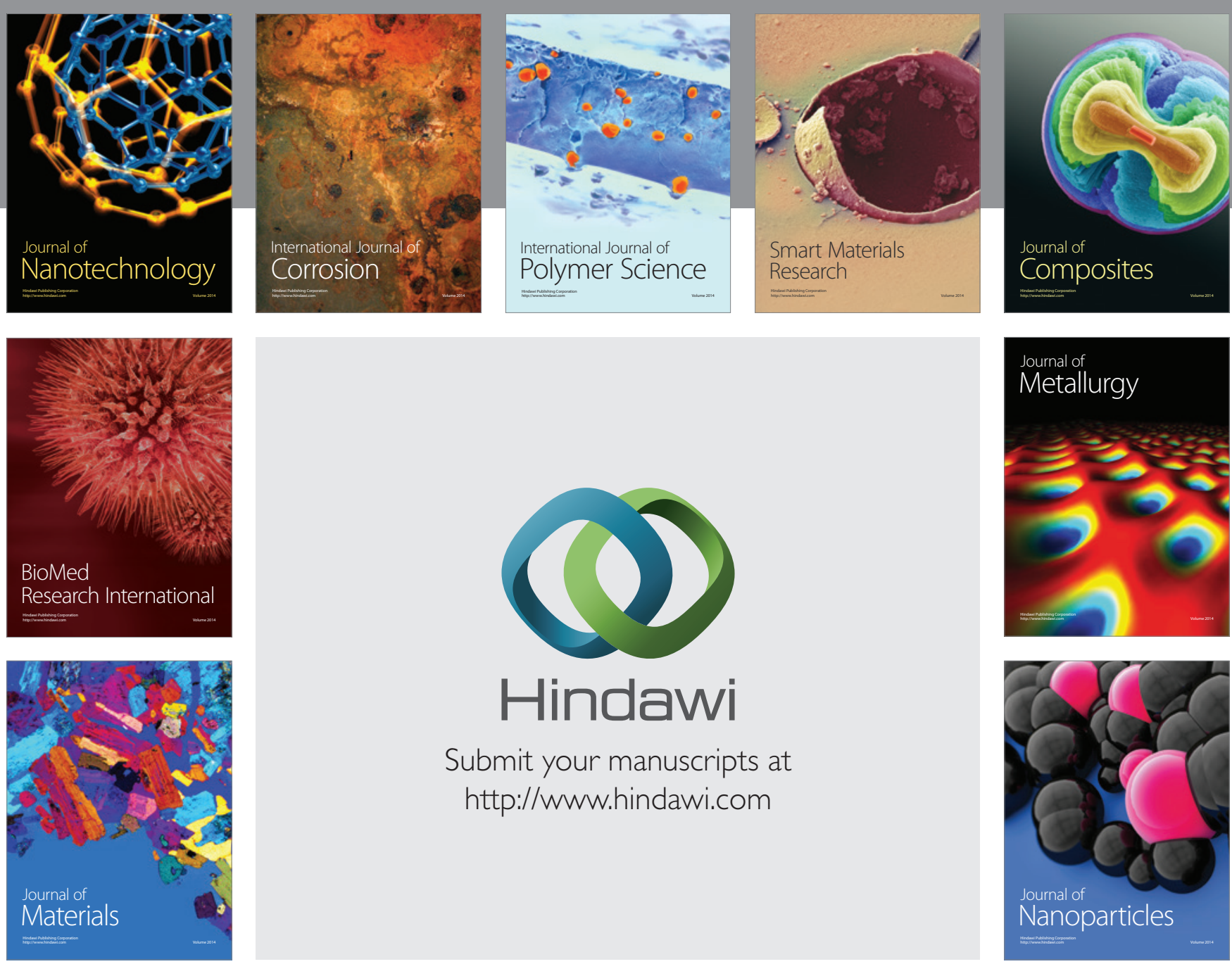

Submit your manuscripts at http://www.hindawi.com
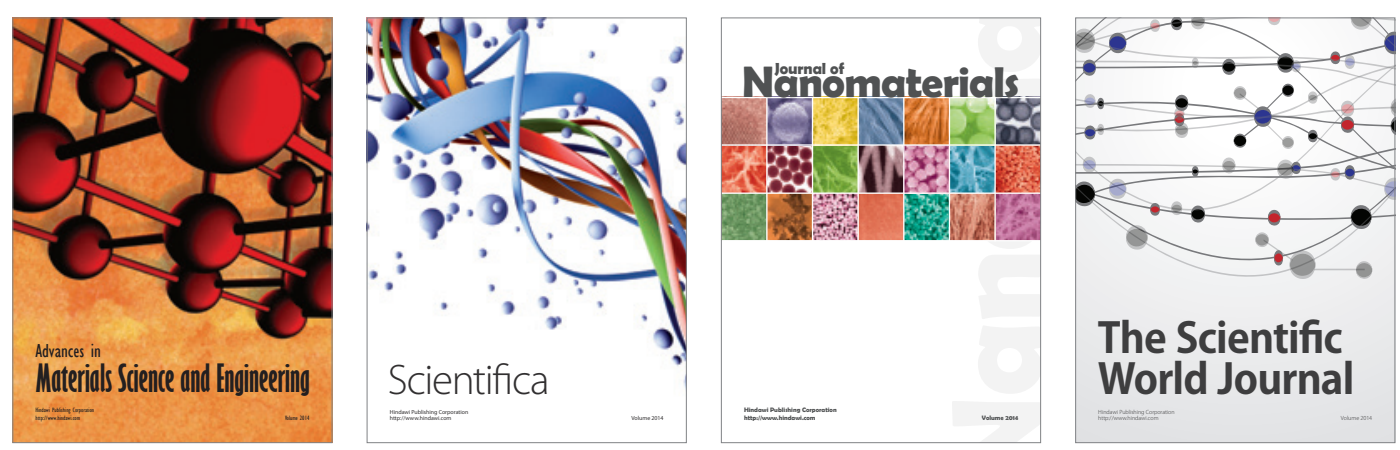

\section{The Scientific World Journal}
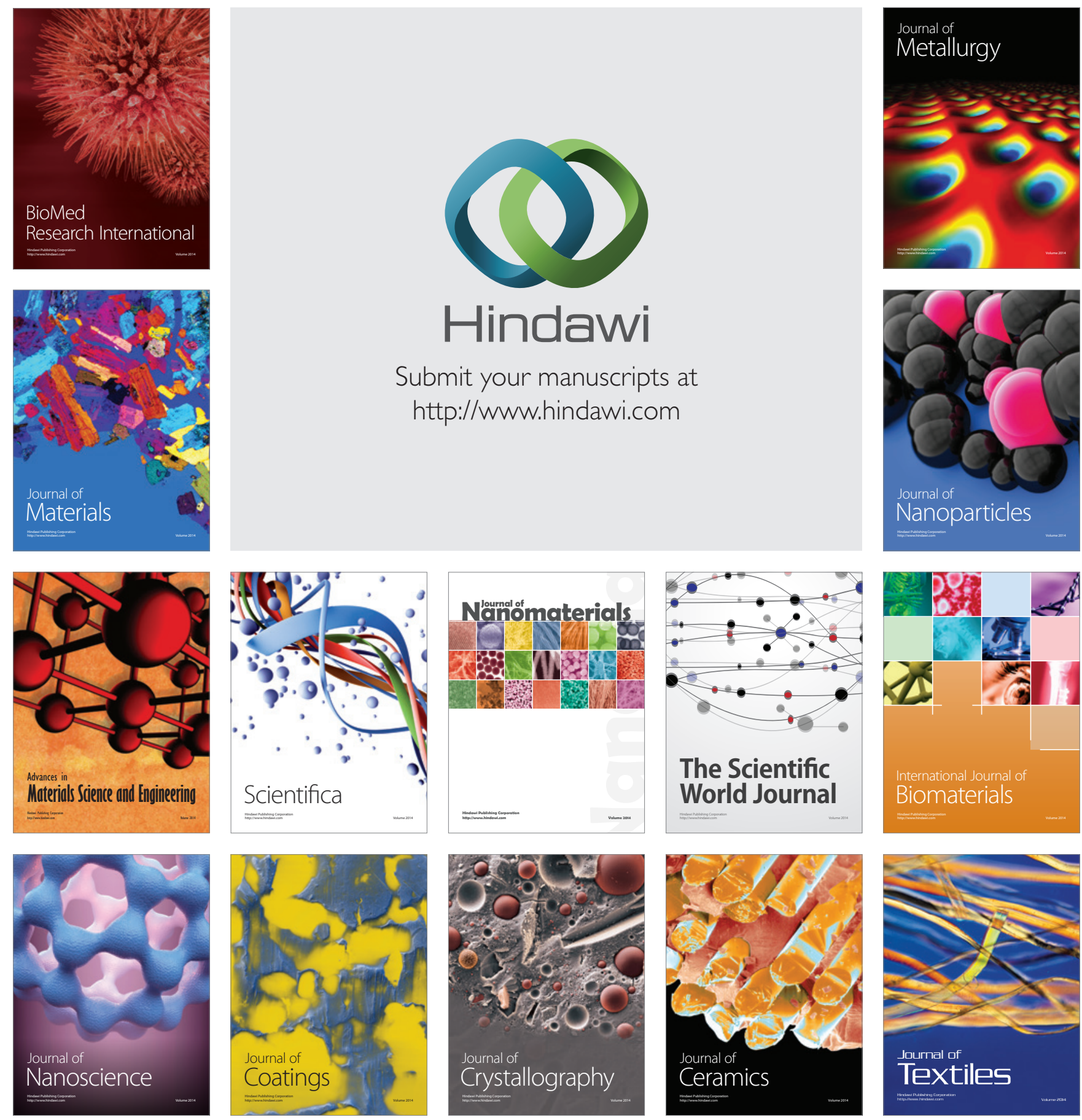